\title{
Alpha-7 nicotinic acetylcholine receptor agonists in intracerebral hemorrhage: an evaluation of the current evidence for a novel therapeutic agent
}

\author{
Eric S. Sussman, B.S., ${ }^{1}$ Christopher P. Kellner, M.D., ${ }^{1}$ Michael M. MCDowell, B.S., ${ }^{1}$ \\ Samuel S. Bruce, M.A., ${ }^{1}$ Simon G. Heuts, B.S., 1 Zong Zhuang, B.S., ${ }^{1}$ \\ Rachel A. Bruce, B.A., 1 Jan Clatssen, M.D., Ph.D., ${ }^{2}$ and E. Sander Connolly JR., M.D. ${ }^{1}$ \\ Departments of ${ }^{1}$ Neurological Surgery and ${ }^{2}$ Neurology, Columbia University, New York, New York
}

\begin{abstract}
Intracerebral hemorrhage (ICH) is the most deadly and least treatable subtype of stroke, and at the present time there are no evidence-based therapeutic interventions for patients with this disease. Secondary injury mechanisms are known to cause substantial rates of morbidity and mortality following $\mathrm{ICH}$, and the inflammatory cascade is a major contributor to this post-ICH secondary injury. The alpha-7 nicotinic acetylcholine receptor $(\alpha 7-\mathrm{nAChR})$ agonists have a well-established antiinflammatory effect and have been shown to attenuate perihematomal edema volume and to improve functional outcome in experimental ICH. The authors evaluate the current evidence for the use of an $\alpha 7-$ nAChR agonist as a novel therapeutic agent in patients with ICH.

(http://thejns.org/doi/abs/10.3171/2013.2.FOCUS1315)
\end{abstract}

KEY WoRDS - intracerebral hemorrhage $\quad$ nicotinic acetylcholine receptor •
alpha-7 agonist

I NTRACEREBRAL hemorrhage accounts for approximately $15 \%$ of all strokes in the US and has higher morbidity and mortality rates than any other stroke subtype. ${ }^{4,10,11,38,44,57}$ The prognosis for patients with ICH remains poor, with up to $30 \%$ mortality and nearly $90 \%$ of patients left with some form of disability.,10,44,58 Although much has been learned about the mechanisms of injury in ICH, successful disease-modifying strategies remain elusive.$^{20}$ In an effort to identify novel therapeutic interventions, much work has been done to elucidate the underlying pathophysiology of ICH. Although the initial hemorrhage can be devastating, secondary injury mechanisms are responsible for a significant amount of damage to the CNS. ${ }^{1,9}$ Attention has therefore been focused on targeting these secondary injury pathways.

One of these secondary injury pathways is the inflammatory cascade. ${ }^{19,53,56}$ In response to the deposition of immunogenic and biochemically reactive blood products in the perihematomal brain parenchyma, there is a significant amount of cellular infiltration and inflammation. ${ }^{1}$ Furthermore, NF- $\mathrm{KB}$ is activated within hours after the onset of hemorrhage,,$^{1,14,50,51}$ and in turn results in

\footnotetext{
Abbreviations used in this paper: $\alpha 7-\mathrm{nAChR}=$ alpha- 7 nicotinic acetylcholine receptor; $\mathrm{BWC}=$ brain water content; $\mathrm{ICH}=$ intracerebral hemorrhage; LPS = lipopolysaccharide; NF- $\mathrm{KB}=$ nuclear factor $\mathrm{\kappa B}$; PHE = perihematomal edema; PI3K = phosphatidylinositol 3-kinase; TNF- $\alpha=$ tumor necrosis factor $-\alpha$.
}

the production of a wide variety of inflammatory mediators, including cytokines, adhesion molecules, apoptotic regulators, stress response genes, and inflammatory en-

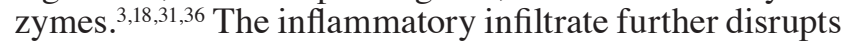
the surrounding brain parenchyma, leading to neuronal damage and subsequent cellular apoptosis. This post-ICH inflammatory response has therefore been a target of interest in the quest to develop novel therapeutics for the treatment of ICH.

The $\alpha 7-n A C h R$ agonists have been identified as particularly potent antiinflammatory agents, and $\alpha 7-n A C h R s$ are expressed in a variety of cell types in the mammalian brain. ${ }^{7,26,45}$ Importantly, the downstream antiinflammatory effects of $\alpha 7$ stimulation involve a downregulation of the ubiquitous $N F-\kappa B,,^{21,40,54}$ suggesting that this class of drug may have a therapeutic benefit in patients with $\mathrm{ICH}$. In this study we evaluate the current evidence for the use of an $\alpha 7-n A C h R$ agonist as a novel therapeutic agent in patients with $\mathrm{ICH}$.

\section{Antiinflammatory Effects of $\alpha 7$ Stimulation}

There is a highly conserved, endogenous mechanism by which organisms are able to control the magnitude of immune responses and prevent excessive inflammation. This physiological mechanism - the so-called cholinergic antiinflammatory pathway-is mediated by acetylcholine release from the vagus nerve. ${ }^{47}$ It follows, therefore, that 


\section{E. S. Sussman et al.}

acetylcholine agonists have a well-established antiinflammatory effect. For instance, nicotine-the prototypical nonselective acetylcholine agonist-has antiinflammatory effects in multiple cell types and has been shown to quell inflammation in a variety of inflammation-related processes..$^{30,37,55}$

The $\alpha 7$ subunit of the $\mathrm{nAChR}$ has been identified as the principal mediator of this cholinergic antiinflammatory pathway. Macrophages exposed to antisense oligonucleotides specific to the $\alpha 7$ subunit demonstrate a significantly blunted antiinflammatory response in the presence of cholinergic agonists, compared with control macrophages exposed to antisense oligonucleotides specific to $\alpha 1$ and a10 subunits, which have not been implicated in the cholinergic antiinflammatory pathway. ${ }^{52}$ Furthermore, knockout mice deficient in the $\alpha 7-n A C h R$ subunit have higher serum TNF- $\alpha$ levels following endotoxin exposure compared with wild-type mice, and macrophages isolated from these $\alpha 7$-deficient mice are refractory to the antiinflammatory effects of cholinergic agonists. The administration of GTS-21, a known agonist at the $\alpha 7$ subunit, reduces serum TNF- $\alpha$ levels and thereby improves outcomes in a murine model of endotoxemia and severe sepsis, ${ }^{35}$ and GTS-21 also decreases the severity of experimentally induced pancreatitis. ${ }^{49}$ Similarly, tropisetron, another drug with agonist activity at the $\alpha 7$ subunit, inhibits the LPS-induced production of TNF- $\alpha$ and IL-1 $\beta$ from human monocytes. ${ }^{41}$ However, these agents bind to other targets in addition to the $\alpha 7-n A C h R$ subunit, therefore making it difficult to ascertain the specific contribution of the $\alpha 7$ subunit to this antiinflammatory effect.

More recently, $\alpha 7$-subtype-selective $\mathrm{nAChR}$ agonists have been used to investigate the antiinflammatory effect of the $\alpha 7$ subunit more directly. The administration of a subtype-selective $\alpha 7-n A C h R$ agonist, A-833834, causes a reduction in LPS-induced TNF- $\alpha$ release in mouse peritoneal macrophages, as well as in human whole blood in vitro and in mouse serum in vivo. ${ }^{25}$ Another selective $\alpha 7$ agonist, AR-R17779, leads to an improvement in clinical arthritis and a reduction in synovial inflammation in experimental (collagen-induced) arthritis in mice, and this is accompanied by a reduction in TNF- $\alpha$ levels in both plasma and synovial tissue. ${ }^{48}$ In the brain in particular, rats treated with a selective $\alpha 7$ agonist following traumatic brain injury demonstrate reduced microglial activation and increased cortical tissue sparing as well as improved performance on functional outcome assessments. ${ }^{13}$ In addition, nicotine leads to an attenuation of microglial activation and a reduction in TNF- $\alpha$ levels in rodents following LPS-induced inflammation of the substantia nigra, and this effect is blocked by the addition of $\alpha$-bungarotoxin, a selective $\alpha 7$ antagonist. ${ }^{33}$

\section{Inflammation as a Driver of Post-ICH Edema}

Perihematomal edema is a well-known sequela of $\mathrm{ICH}$, and increased PHE volume has been identified as an independent predictor of worse clinical outcomes ${ }^{39}$ It has been demonstrated that edema formation in experimental ICH is dependent on circulating white blood cells and platelets, ${ }^{17}$ leading to the hypothesis that inflamma- tion plays a causative role in PHE formation. More recently, TNF- $\alpha$ has been shown to increase in the serum and plasma of patients with spontaneous $\mathrm{ICH}$, and the degree of rise is correlated with the magnitude of PHE. ${ }^{5,8,16}$ Furthermore, the downregulation of cytokine activity via adenovirus-mediated transfer of the $I L-1$ receptor antagonist gene into the brain prior to hematoma induction in experimental ICH causes a significant reduction in PHE volume. ${ }^{28,29}$ In humans, the antiinflammatory agent celecoxib has been shown to reduce PHE volume in patients with ICH compared with controls. ${ }^{33}$

\section{Results of $\alpha 7$ Stimulation in Experimental ICH}

Given that the inflammatory reaction is a major driver of the development of post-ICH edema, and that the $\alpha 7$ nAChR mediates downstream antiinflammatory effects, it follows, therefore, that $\alpha 7-n A C h R$ stimulation may lead to a reduction in post-ICH edema. This hypothesis has been tested in experimental ICH.

Krafft et al. ${ }^{23}$ administered a subtype-selective $\alpha 7$ agonist-either PHA-543613 or PNU-282987-1 hour after induction of hemorrhage in a murine model of $\mathrm{ICH}$. To identify more precisely the molecular pathways involved in any observed effects of the experimental treatments, select cohorts of mice also received methyllycaconitine, an $\alpha 7-n A C h R$ antagonist, and/or wortmannin, an inhibitor of the PI3K-Akt signaling pathway located downstream of the $\alpha 7-n A C h R$. These experiments demonstrated a significant attenuation in behavioral deficits and a reduction in BWC in mice receiving $\alpha 7-n A C h R$ agonist, and these effects were abolished by coadministration of methyllycaconitine and/or wortmannin, suggesting that the observed effect is mediated by $\alpha 7$-induced PI3K-Akt signaling. Importantly, the PI3K-Akt signaling pathway leads to a reduction in neuronal apoptosis in a variety of disease models, ${ }^{7,43,45}$ and so it is likely that the observed effects of $\alpha 7-n A C h R$ stimulation are at least partially due to a reduction in post-ICH apoptosis.

In a similar series of experiments, Hijioka et al..$^{15}$ demonstrated an increase in the number of surviving neurons and an attenuation of the inflammatory cell infiltrate in the perihematomal region, but no significant effect on BWC (functional outcome was not assessed in this study). This lack of effect on BWC is in contrast to the findings of Krafft et al., as described above. As suggested by Hijioka et al., it is possible that these contradictory findings may be attributable to a difference in the administered dose $(10 \mathrm{mg} / \mathrm{kg}$ vs $12 \mathrm{mg} / \mathrm{kg}$ ) or a difference in the particular mouse strains used. However, it is likely that the experimental methods used in this study also contributed to the lack of effect on BWC. In particular, experimental ICH was induced using a collagenase injection model, which is less representative of human spontaneous ICH than the alternative autologous blood injection model, as was used by Krafft et al. Mechanistically, the collagenase injection model leads to hemorrhage by proteolytically destroying blood vessel walls in the region of the injection. This leads to massive edema that is not inflammation driven, and so the lack of effect of an antiinflammatory agent (that is, an $\alpha 7$ agonist) on BWC is not surprising. In addition, the protocol used by Hijioka 
et al. for the determination of BWC involved drying brain samples at a lower temperature $\left(75^{\circ} \mathrm{C}\right.$ vs $\left.100^{\circ} \mathrm{C}\right)$ and for less time (12 hours vs 24 hours) compared with Krafft et al., as well as with the vast majority of other research groups using this technique for calculation of BWC. 2,12,24,27,46 It follows, therefore, that Hijioka et al. probably underestimated the effect of $\alpha 7$ stimulation on BWC.

\section{Clinical Feasibility of an $\alpha 7-n A C h R$ Agonist as a Novel Therapeutic Agent in Patients With ICH}

Although the safety of $\alpha 7-n A C h R$ agonists has not been specifically evaluated in the population of patients with ICH, a number of different $\alpha 7$ agonists have been administered to humans for other indications and have been well tolerated. ${ }^{6,22,32,42}$ Furthermore, although the optimal timing of drug administration is not currently known, the preclinical data support postictus drug administration. In particular, in the study described above, Hijioka et al. administered PNU-282987 at different initial time points relative to ICH onset (1 hour prior, and 3, 6, and 12 hours after), and demonstrated a time-dependent decline in efficacy that remained statistically significant until 6 hours after ICH onset, with the greatest efficacy being observed with initial dosing at 3 hours after ICH onset.

\section{Conclusions}

There is strong preclinical evidence for a therapeutic benefit of an $\alpha 7-n A C h R$ agonist in the setting of experimental $\mathrm{ICH}$, and there is clinical evidence of safety and tolerability of such an agent in humans. More thorough investigation is necessary to evaluate the optimal timing of drug administration after ICH onset, and Phase I clinical trials are warranted to evaluate the safety of this drug in the population of patients with ICH.

\section{Disclosure}

Michael McDowell and Eric Sussman are recipients of a Clinical Research Fellowship from the Doris Duke Charitable Foundation.

Author contributions to the study and manuscript preparation include the following. Conception and design: Connolly, Sussman, Kellner. Acquisition of data: Connolly, Sussman. Analysis and interpretation of data: Connolly, Kellner, SS Bruce. Drafting the article: Connolly, Sussman, RA Bruce. Critically revising the article: Connolly, Kellner, McDowell, SS Bruce, Heuts, Zhuang. Reviewed submitted version of manuscript: Connolly, Claassen.

\section{References}

1. Aronowski J, Hall CE: New horizons for primary intracerebral hemorrhage treatment: experience from preclinical studies. Neurol Res 27:268-279, 2005

2. Ayer RE, Sugawara T, Chen W, Tong W, Zhang JH: Melatonin decreases mortality following severe subarachnoid hemorrhage. J Pineal Res 44:197-204, 2008

3. Barnes PJ, Karin M: Nuclear factor- $\kappa b$ : a pivotal transcription factor in chronic inflammatory diseases. N Engl J Med 336: 1066-1071, 1997

4. Broderick J, Connolly S, Feldmann E, Hanley D, Kase C, Krieger D, et al: Guidelines for the management of spontaneous intracerebral hemorrhage in adults: 2007 update: a guideline from the American Heart Association/American Stroke Association Stroke Council, High Blood Pressure Research Council, and the Quality of Care and Outcomes in Research Interdisciplinary Working Group. Stroke 38:2001-2023, 2007

5. Castillo J, Dávalos A, Alvarez-Sabín J, Pumar JM, Leira R, Silva Y, et al: Molecular signatures of brain injury after intracerebral hemorrhage. Neurology 58:624-629, 2002

6. Deutsch SI, Schwartz BL, Schooler NR, Rosse RB, Mastropaolo J, Gaskins B: First administration of cytidine diphosphocholine and galantamine in schizophrenia: a sustained alpha7 nicotinic agonist strategy. Clin Neuropharmacol 31: 34-39, 2008

7. Duris K, Manaenko A, Suzuki H, Rolland WB, Krafft PR, Zhang JH: $\alpha 7$ nicotinic acetylcholine receptor agonist PNU282987 attenuates early brain injury in a perforation model of subarachnoid hemorrhage in rats. Stroke 42:3530-3536, 2011

8. Dziedzic T, Bartus S, Klimkowicz A, Motyl M, Slowik A, Szczudlik A: Intracerebral hemorrhage triggers interleukin-6 and interleukin-10 release in blood. Stroke 33:2334-2335, 2002

9. Fainardi E, Borrelli M, Saletti A, Sarubbo S, Roversi G, Bernardoni A, et al: Temporal changes in perihematomal apparent diffusion coefficient values during the transition from acute to subacute phases in patients with spontaneous intracerebral hemorrhage. Neuroradiology 55:145-156, 2013

10. Feigin VL, Lawes CMM, Bennett DA, Barker-Collo SL, Parag $\mathrm{V}$ : Worldwide stroke incidence and early case fatality reported in 56 population-based studies: a systematic review. Lancet Neurol 8:355-369, 2009

11. Flaherty ML, Woo D, Haverbusch M, Sekar P, Khoury J, Sauerbeck L, et al: Racial variations in location and risk of intracerebral hemorrhage. Stroke 36:934-937, 2005

12. Fujii M, Duris K, Altay O, Soejima Y, Sherchan P, Zhang JH: Inhibition of Rho kinase by hydroxyfasudil attenuates brain edema after subarachnoid hemorrhage in rats. Neurochem Int 60:327-333, 2012

13. Guseva MV, Hopkins DM, Scheff SW, Pauly JR: Dietary choline supplementation improves behavioral, histological, and neurochemical outcomes in a rat model of traumatic brain injury. J Neurotrauma 25:975-983, 2008

14. Hickenbottom SL, Grotta JC, Strong R, Denner LA, Aronowski J: Nuclear factor-kappaB and cell death after experimental intracerebral hemorrhage in rats. Stroke 30:2472-2478, 1999

15. Hijioka M, Matsushita H, Ishibashi H, Hisatsune A, Isohama Y, Katsuki H: $\alpha 7$ Nicotinic acetylcholine receptor agonist attenuates neuropathological changes associated with intracerebral hemorrhage in mice. Neuroscience 222:10-19, 2012

16. Hua Y, Wu J, Keep RF, Nakamura T, Hoff JT, Xi G: Tumor necrosis factor-alpha increases in the brain after intracerebral hemorrhage and thrombin stimulation. Neurosurgery 58: 542-550, 2006

17. Kane PJ, Modha P, Strachan RD, Cook S, Chambers IR, Clayton $\mathrm{CB}$, et al: The effect of immunosuppression on the development of cerebral oedema in an experimental model of intracerebral haemorrhage: whole body and regional irradiation. J Neurol Neurosurg Psychiatry 55:781-786, 1992

18. Karin M: How NF-kappaB is activated: the role of the IkappaB kinase (IKK) complex. Oncogene 18:6867-6874, 1999

19. Keep RF, Hua Y, Xi G: Intracerebral haemorrhage: mechanisms of injury and therapeutic targets. Lancet Neurol 11: 720-731, 2012

20. Kellner CP, Connolly ES Jr: Neuroprotective strategies for intracerebral hemorrhage: trials and translation. Stroke 41 (10 Suppl):S99-S102, 2010

21. Kitaoka T, Hua Y, Xi G, Hoff JT, Keep RF: Delayed argatroban treatment reduces edema in a rat model of intracerebral hemorrhage. Stroke 33:3012-3018, 2002

22. Kox M, Pompe JC, Gordinou de Gouberville MC, van der Hoeven JG, Hoedemaekers CW, Pickkers P: Effects of the $\alpha 7$ 


\section{E. S. Sussman et al.}

nicotinic acetylcholine receptor agonist GTS-21 on the innate immune response in humans. Shock 36:5-11, 2011

23. Krafft PR, Altay O, Rolland WB, Duris K, Lekic T, Tang J, et al: $\alpha 7$ nicotinic acetylcholine receptor agonism confers neuroprotection through GSK-3 $\beta$ inhibition in a mouse model of intracerebral hemorrhage. Stroke 43:844-850, 2012

24. Lee S, Jadhav V, Ayer RE, Rojas H, Hyong A, Lekic T, et al: Dual effects of melatonin on oxidative stress after surgical brain injury in rats. J Pineal Res 46:43-48, 2009

25. Li J, Mathieu SL, Harris R, Ji J, Anderson DJ, Malysz J, et al: Role of $\alpha 7$ nicotinic acetylcholine receptors in regulating tumor necrosis factor- $\alpha$ (TNF- $\alpha$ ) as revealed by subtype selective agonists. J Neuroimmunol 239:37-43, 2011

26. Lightfoot AP, Kew JNC, Skidmore J: Alpha7 nicotinic acetylcholine receptor agonists and positive allosteric modulators. Prog Med Chem 46:131-171, 2008

27. Louin G, Marchand-Verrecchia C, Palmier B, Plotkine M, Jafarian-Tehrani M: Selective inhibition of inducible nitric oxide synthase reduces neurological deficit but not cerebral edema following traumatic brain injury. Neuropharmacology 50:182-190, 2006

28. Masada T, Hua Y, Xi G, Yang GY, Hoff JT, Keep RF: Attenuation of intracerebral hemorrhage and thrombin-induced brain edema by overexpression of interleukin-1 receptor antagonist. J Neurosurg 95:680-686, 2001

29. Masada T, Hua Y, Xi G, Yang GY, Hoff JT, Keep RF, et al: Overexpression of interleukin-1 receptor antagonist reduces brain edema induced by intracerebral hemorrhage and thrombin. Acta Neurochir Suppl 86:463-467, 2003

30. McGrath J, McDonald JWD, Macdonald JK: Transdermal nicotine for induction of remission in ulcerative colitis. Cochrane Database Syst Rev (4):CD004722, 2004

31. Nolan GP, Baltimore D: The inhibitory ankyrin and activator Rel proteins. Curr Opin Genet Dev 2:211-220, 1992

32. Othman AA, Lenz RA, Zhang J, Li J, Awni WM, Dutta S: Single- and multiple-dose pharmacokinetics, safety, and tolerability of the selective alpha7 neuronal nicotinic receptor agonist, ABT-107, in healthy human volunteers. J Clin Pharmacol 51:512-526, 2011

33. Park HJ, Lee PH, Ahn YW, Choi YJ, Lee G, Lee DY, et al: Neuroprotective effect of nicotine on dopaminergic neurons by anti-inflammatory action. Eur J Neurosci 26:79-89, 2007

34. Park HK, Lee SH, Chu K, Roh JK: Effects of celecoxib on volumes of hematoma and edema in patients with primary intracerebral hemorrhage. J Neurol Sci 279:43-46, 2009

35. Pavlov VA, Ochani M, Yang LH, Gallowitsch-Puerta M, Ochani K, Lin X, et al: Selective alpha7-nicotinic acetylcholine receptor agonist GTS-21 improves survival in murine endotoxemia and severe sepsis. Crit Care Med 35:1139-1144, 2007

36. Perry VH, Andersson PB, Gordon S: Macrophages and inflammation in the central nervous system. Trends Neurosci 16:268-273, 1993

37. Pullan RD, Rhodes J, Ganesh S, Mani V, Morris JS, Williams GT, et al: Transdermal nicotine for active ulcerative colitis. $\mathbf{N}$ Engl J Med 330:811-815, 1994

38. Sacco S, Marini C, Toni D, Olivieri L, Carolei A: Incidence and 10-year survival of intracerebral hemorrhage in a population-based registry. Stroke 40:394-399, 2009

39. Sansing LH, Messe SR, Cucchiara BL, Lyden PD, Kasner SE: Anti-adrenergic medications and edema development after intracerebral hemorrhage. Neurocrit Care 14:395-400, 2011

40. Schaden E, Kozek-Langenecker SA: Direct thrombin inhibitors: pharmacology and application in intensive care medicine. Intensive Care Med 36:1127-1137, 2010

41. Seide MF, Ulrich-Merzenich G, Fiebich B, Candelario-Jalil E, Koch FW, Vetter H: Tropisetron inhibits serotonin-induced PGE2 release from macrophage-like synovial cells in serumfree tissue culture. Scand J Rheumatol Suppl 119:33, 2004
42. Shaffer CL, Gunduz M, Scialis RJ, Fang AF: Metabolism and disposition of a selective alpha(7) nicotinic acetylcholine receptor agonist in humans. Drug Metab Dispos 35:1188-1195, 2007

43. Shaw S, Bencherif M, Marrero MB: Janus kinase 2, an early target of alpha 7 nicotinic acetylcholine receptor-mediated neuroprotection against Abeta-(1-42) amyloid. J Biol Chem 277:44920-44924, 2002

44. Sudlow CL, Warlow CP: Comparable studies of the incidence of stroke and its pathological types: results from an international collaboration. Stroke 28:491-499, 1997

45. Takada-Takatori Y, Kume T, Sugimoto M, Katsuki H, Sugimoto H, Akaike A: Acetylcholinesterase inhibitors used in treatment of Alzheimer's disease prevent glutamate neurotoxicity via nicotinic acetylcholine receptors and phosphatidylinositol 3-kinase cascade. Neuropharmacology 51:474-486, 2006

46. Timaru-Kast R, Luh C, Gotthardt P, Huang C, Schäfer MK, Engelhard K, et al: Influence of age on brain edema formation, secondary brain damage and inflammatory response after brain trauma in mice. PLoS ONE 7:e43829, 2012

47. Tracey KJ: The inflammatory reflex. Nature 420:853-859, 2002

48. van Maanen MA, Lebre MC, van der Poll T, LaRosa GJ, Elbaum D, Vervoordeldonk MJ, et al: Stimulation of nicotinic acetylcholine receptors attenuates collagen-induced arthritis in mice. Arthritis Rheum 60:114-122, 2009

49. van Westerloo DJ, Giebelen IAJ, Florquin S, Daalhuisen J, Bruno MJ, de Vos AF, et al: The cholinergic anti-inflammatory pathway regulates the host response during septic peritonitis. J Infect Dis 191:2138-2148, 2005

50. Wagner KR, Sharp FR, Ardizzone TD, Lu A, Clark JF: Heme and iron metabolism: role in cerebral hemorrhage. J Cereb Blood Flow Metab 23:629-652, 2003

51. Wagner KR, Xi G, Hua Y, Kleinholz M, de Courten-Myers GM, Myers RE, et al: Lobar intracerebral hemorrhage model in pigs: rapid edema development in perihematomal white matter. Stroke 27:490-497, 1996

52. Wang H, Yu M, Ochani M, Amella CA, Tanovic M, Susarla S, et al: Nicotinic acetylcholine receptor alpha7 subunit is an essential regulator of inflammation. Nature 421:384-388, 2003

53. Wang J: Preclinical and clinical research on inflammation after intracerebral hemorrhage. Prog Neurobiol 92:463-477, 2010

54. Wang J, Tsirka SE: Neuroprotection by inhibition of matrix metalloproteinases in a mouse model of intracerebral haemorrhage. Brain 128:1622-1633, 2005

55. Wang X, Yang Z, Xue B, Shi H: Activation of the cholinergic antiinflammatory pathway ameliorates obesity-induced inflammation and insulin resistance. Endocrinology 152:836846,2011

56. Xi G, Keep RF, Hoff JT: Mechanisms of brain injury after intracerebral haemorrhage. Lancet Neurol 5:53-63, 2006

57. Zahuranec DB, Gonzales NR, Brown DL, Lisabeth LD, Longwell PJ, Eden SV, et al: Presentation of intracerebral haemorrhage in a community. J Neurol Neurosurg Psychiatry 77: 340-344, 2006

58. Zhang X, Li H, Hu S, Zhang L, Liu C, Zhu C, et al: Brain edema after intracerebral hemorrhage in rats: the role of inflammation. Neurol India 54:402-407, 2006

Manuscript submitted January 14, 2013.

Accepted February 13, 2013.

Please include this information when citing this paper: DOI: 10.3171/2013.2.FOCUS1315.

Address correspondence to: E. Sander Connolly, M.D., The Neurological Institute, 710 West 168th Street, New York, New York 10032.email: esc5@columbia.edu. 